\title{
Aged Garlic Extract and One of the Constituent, (+)-(2S,3R)-Dehydrodiconiferyl Alcohol, Inhibits Alkaline Phosphatase Activity Induced by Inflammation Factors in Human Vascular Smooth Muscle Cells
}

\author{
Takahiro Yamakawa $^{1}$, Toshiaki Matsutomo ${ }^{2}$, Thomas Hofmann ${ }^{2}$, Yukihiro Kodera ${ }^{*}$ \\ ${ }^{1}$ Central Research Institute of Wakunaga Pharmaceutical Co. Ltd., Hiroshima, Japan; ${ }^{2}$ Technische Universität München, Freising, \\ Germany.

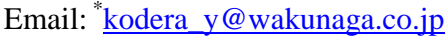

Received November $7^{\text {th }}$, 2013; revised December $7^{\text {th }}$, 2013; accepted December $17^{\text {th }}, 2013$

Copyright (C 2014 Takahiro Yamakawa et al. This is an open access article distributed under the Creative Commons Attribution License, which permits unrestricted use, distribution, and reproduction in any medium, provided the original work is properly cited. In accordance of the Creative Commons Attribution License all Copyrights (C) 2014 are reserved for SCIRP and the owner of the intellectual property Takahiro Yamakawa et al. All Copyright (C 2014 are guarded by law and by SCIRP as a guardian.

\section{ABSTRACT}

Previous clinical study showed that aged garlic extract (AGE) has a preventive effect of vascular calcification in patients with coronary artery diseases. It has been reported that vascular smooth muscle cells (VSMC) and inflammatory cells including macrophages and lymphocytes migrate to sub-intimal region where atherosclerotic plaques are formed, and VSMC can differentiate into osteoblast-like cells, which are represented by the induction of alkaline phosphatase (ALP). We found that primary human coronary artery smooth muscle cells (HCASMC) showed the increased ALP activity, when cultured in the medium containing ascorbic acid, $\beta$-glycerophosphate, dexamethasone (IM), and supplemented with conditioned medium from macrophages (MCM). Then we tested the effect of AGE subdivided fractions and several compounds found in AGE, and then found that ((+)-(2S,3R)-Dehydrodiconiferyl alcohol, a dilignol compound existed in hydrophobic fraction of AGE, inhibited ALP activity in HCASMC.

\section{KEYWORDS}

Vascular Smooth Muscle; Alkaline Phosphatase; Aged Garlic Extract; Dehydrodiconiferyl Alcohol

\section{Introduction}

The population suffering from an atherosclerosis is increasing all over the world. It has been known that vascular calcification is a common and clinically significant feature of advanced atherosclerosis. The amount of calcified atherosclerotic plaques, especially in coronary artery is not only a strong predictor, but also a risk factor of coronary heart disease [1,2]. These calcified lesions express bone-related proteins, including alkaline phosphatase (ALP), bone morphogenetic proteins, runt-related gene 2 product, and osteopontin [3-8], and contain inflammatory cells, such as monocytes, macrophages, and lymphocytes $[9,10]$. These observations suggest that

\footnotetext{
${ }^{*}$ Corresponding author.
}

atherosclerotic plaque calcification, associated with inflammatory reactions, may be similar to the process of bone mineralization.

Smooth muscle cells are the predominant cell type found in the arterial wall and are essential for the structural and functional integrity of the vessel. Unlike most cell types that undergo terminal differentiation, smooth muscle retains substantial phenotypic plasticity in response to various stimuli including inflammatory cytokines. It has been shown that vascular smooth muscle cells (VSMC) can undergo a phenotypic transition into osteoblast-like features in vivo [11], and that inflammatory mediators promote differentiation of VSMC into osteoblast-like cells in culture [12,13], resembling atherosclerotic calcification observed in human tissues. These 
results suggest that VSMC are involved in vascular calcification in atherosclerotic plaques.

Although genetic factors definitely play a role in determining individual susceptibility to atherosclerosis, diet and life style are still major contributors to the disease, suggesting that dietary supplements may help to prevent atherosclerosis. Aged garlic extract (AGE) is produced by aqueous ethanol extraction of raw garlic (Allium sativum L.) for more than 10 months, resulting in enrichment of water-soluble sulfur compounds and reduction in harsh compounds [14]. Many clinical trials showed that AGE has anti-atherosclerotic effects, such as lowering cholesterol [15], inhibiting platelet aggregation [16,17], and suppressing low-density lipoprotein (LDL) oxidation [18]. It has been also found that the dietary supplementation of AGE retards coronary calcification in patients having coronary artery disease with calcified plaques $[19,20]$. AGE, however, does not lower cholesterol levels or reduce the oxidation of LDL in this trial, suggesting that the retardation in vascular calcification by AGE may be due to some mechanisms other than cholesterol-lowering and anti-oxidative effects.

Based on these findings, we hypothesized that the reduction in coronary calcified plaque by supplementation of AGE was partly due to the suppression of osteogenic differentiation in VSMC. In present study, we showed that VSMC showed osteoblastic phenotype, which was represented by the induction of alkaline phosphatase (ALP) in the presence of glucocorticoid and inflammatory mediators, and that AGE, its subdivided fractions and the compound isolated from AGE inhibited ALP activity.

\section{Materials and Methods}

\subsection{Materials}

Primary human coronary artery smooth muscle cells (HCASMC), and SMC growth medium (SmGM-2) were purchased from Lonza (Portsmouth, NH). Human monocytic THP-1 cells were purchased from European Collection of Cell Cultures (Salisbury, United Kingdom). Fetal bovine serum (FBS) and BCA protein assay kit were purchased from Thermo Scientific (Rockford, IL). MCI gel CHP20P resin was purchased from Mitsubishi Chemical (Tokyo, Japan). Other reagents were purchased from Sigma-Aldrich (St. Louis, MO), unless otherwise stated.

\subsection{Smooth Muscle Cell Culture}

HCASMC were maintained in SmGM-2, following manufacturer's instructions. HCASMC were seeded at $0.5 \times 10^{5} /$ well/ $0.5 \mathrm{ml}$ in 24-well plates, and grown in
Dulbecco's modified Eagle's medium containing 4.5 g/L D-glucose (DME high glucose medium), supplemented with 15\% FBS for 3 days. Then medium was switched to either induction medium (IM), which contains $50 \mu \mathrm{g} / \mathrm{ml}$ ascorbic acid (AsA), $10 \mathrm{mM} \beta$-glycerophosphate $(\beta \mathrm{GP})$, and $10 \mathrm{nM}$ dexamethasone (Dex). For eliciting inflammatory responses, conditioned medium from THP-1 macrophages (MCM) was added to IM at the concentration of $10 \%$. Cells were maintained up to 7 days, with the medium being replenished every 2 - 3 days.

\subsection{Preparation of Conditioned Medium from THP-1 Macrophages}

Human monocytic THP-1 cells were maintained in RPMI-1640, supplemented with 10\% FBS. To induce differentiation into THP-1 macrophages, THP-1 cells were seeded at $2.7 \times 10^{7} / \mathrm{T} 75 \mathrm{flask} / 18 \mathrm{ml}$ and treated with $400 \mathrm{ng} / \mathrm{ml}$ phorbol 12-myristate-13-acetate for 1 - 3 days. Cells were then extensively washed with PBS, and cultured in $9 \mathrm{ml}$ per T75 flask of DME high glucose medium supplemented with 15\% FBS. After one-day, the culture media were collected and centrifuged. The supernatants were saved as MCM at $-80^{\circ} \mathrm{C}$ until use.

\subsection{Measurement of Alkaline Phosphatase Activity}

The ALP activity was measured as described previously [21] with slight modifications. HCASMC monolayers were washed with PBS, and lysed with $0.2 \mathrm{ml} /$ well of 10 $\mathrm{mM}$ HEPES buffer (pH 7.9), $10 \mathrm{mM} \mathrm{KCl}, 1.5 \mathrm{mM}$ $\mathrm{MgCl}_{2}$, and $0.4 \mathrm{w} / \mathrm{v} \%$ IGEPAL CA-630. Cell lysates were centrifuged at $800 \times \mathrm{g}$ for $5 \mathrm{~min}$ at $4^{\circ} \mathrm{C}$, and the supernatants were saved. The ALP activity in the lysates was determined by measuring the increase in absorbance at $414 \mathrm{~nm}$ in $0.1 \mathrm{M}$ 2-amino-2-methylpropanol $\cdot \mathrm{HCl}$ buffer (pH 10.5) containing $1 \mathrm{mM} \mathrm{MgCl}_{2}$ and $8 \mathrm{mM}$ pnitrophenyl phosphate as a substrate. Protein content of cell lysates was determined by using BCA protein assay kit.

\subsection{Alkaline Phosphatase Activity Staining}

The ALP activity staining was conducted as described previously [22] with slight modifications. Briefly, cell monolayers were fixed with 3.7\% formaldehyde in PBS for $15 \mathrm{~min}$. Cells were washed with distilled water once, and incubated with distilled water for $15 \mathrm{~min}$. Cells were then exposed to ALP staining solution, containing 0.1 $\mathrm{mg} / \mathrm{ml}$ naphthol AS-MX phosphate, $0.6 \mathrm{mg} / \mathrm{ml}$ Fast Blue BB salt, and $2 \mathrm{mM} \mathrm{MgCl}_{2}$ in $0.1 \mathrm{M}$ Tris. $\mathrm{HCl}$ buffer (pH 8.3), for $45 \mathrm{~min}$. Cells were washed with distilled water twice, and microphotographs were taken. 
Phosphatase Activity Induced by Inflammation Factors in Human Vascular Smooth Muscle Cells

\subsection{Calcium Staining (Von Kossa Staining)}

Von Kossa staining was carried out as described previously [22]. Cell monolayers were fixed with $3.7 \%$ formaldehyde in PBS for 10 min. Cells were washed with distilled water twice, and cells were stained with $2.5 \%$ silver nitrate in distilled water for $30 \mathrm{~min}$. Cells were washed with distilled water four times, and microphotographs were taken.

\subsection{Fractionation of Aged Garlic Extract and Preparation of Its Constituent Compounds}

AGE is manufactured as described [23]. After removing ethanol by evaporation, the residue was dissolved in distilled water, and the solution was applied to polyaromatic adsorbent resin, MCI gel CHP20P. Resin was washed with distilled water, and fraction passing through resin was collected as non-adsorbed fraction. Then compounds bound to resin were eluted with a graded methanol (10\%, $50 \%$, and $100 \%$ ), and collected as $10 \%, 50 \%$, and $100 \%$ $\mathrm{MeOH}$ eluates, respectively. Non-adsorbed fraction was separated into fractions containing high molecular and low molecular weight compounds by dialysis membrane (cut off $3500 \mathrm{Da}$ ). We collected fraction containing low molecular weight compounds as hydrophilic fraction. The separation scheme was shown in Figure 1(a). Dehydrodiconiferyl alcohol (DDC) and Dihydrodehydrodiconiferyl alcohol (DDDC) were separated from AGE as described previously [24]. AGE fractions or isolated compounds were added to the medium at concentrations equivalent to 5 to $50 \mathrm{mg} / \mathrm{ml}$ AGE at every replacement of the media. Figure 1(b) showed the concentration of AGE fractions, and dilignols equivalent to $5 \mathrm{mg} / \mathrm{ml}$ AGE. We expressed the concentration of all samples used as being equivalent of AGE concentrations throughout this study.

\subsection{Statistical Analysis}

All experiments were performed with triplicate independent samples, giving qualitatively identical results. Results are expressed as mean \pm SD. Data were analyzed using Student's $t$-test, with $p$ value use $<0.05$ taken to indicate statistical significance.

\section{Results}

\subsection{ALP Activity in HCASMC Treated with Induction Medium}

Previous findings show that HCASMC could undergo osteoblast differentiation in the presence of AsA, $\beta \mathrm{GP}$, and Dex [25-27]. Since inflammatory reactions occur in the atherosclerotic lesions, we tested the possibility that inflammatory stimuli could induce osteoblast differentiation. For this experiment, we used conditioned media from the culture of THP-1 macrophages (MCM) because it has been reported that MCM elicits inflammatory signals [28]. We cultured HCASMC in either IM (serumcontaining DME high glucose medium supplemented with AsA, $\beta \mathrm{GP}$, and Dex) or IM + MCM (IM supplemented with MCM) for 7 days, and measured ALP

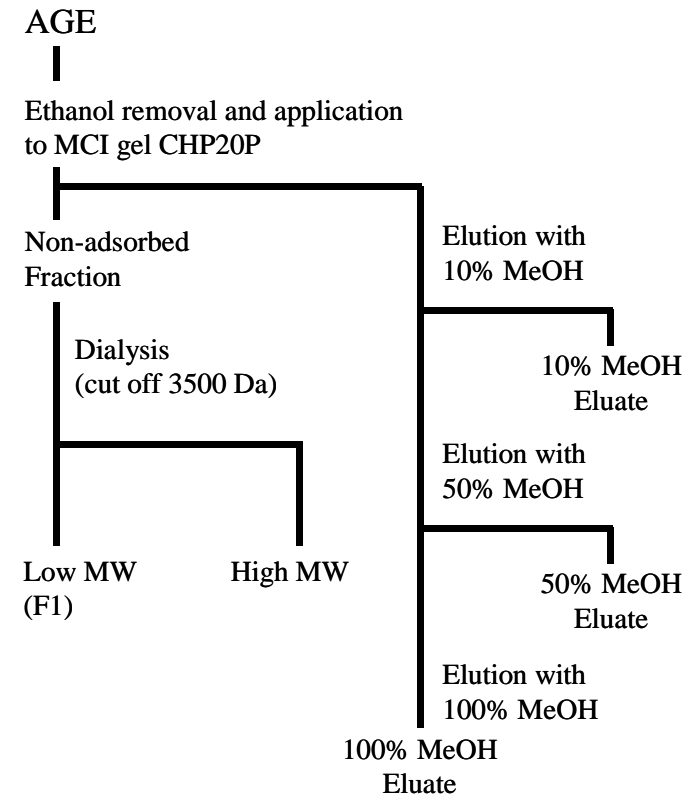

(a)

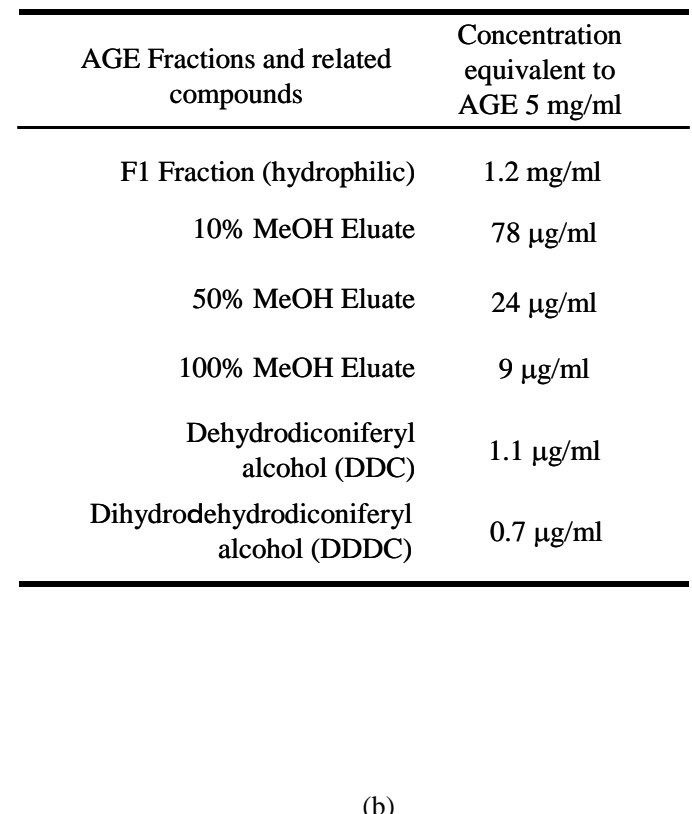

(b)

Figure 1. Preparation of test sample and its constituent content. (a) Separation scheme of AGE subdivide fractions; (b) Concentrations of AGE fractions and related compounds equivalent to $5 \mathrm{mg} / \mathrm{ml} \mathrm{AGE.}$ 
enzyme activity spectrophotometrically. Figure 2(A) showed that ALP activity in IM + MCM-treated HCASMC increased about 10 -fold, compared to that in IM-treated cells in 7 days culture. The addition of 10\% MCM also augmented ALP activity about 3-fold. When HCASMC were treated with both IM and MCM, even greater induction of ALP activity was observed (about 20-fold induction vs. GM-treated cells), which was consistent with the results of ALP activity staining in cells (Figures 2(B)-(E)). The induction of ALP results in the hydrolysis of $\beta \mathrm{GP}$ to liberate inorganic phosphate, followed by the accumulation of calcium phosphate deposits, as it happens in ossification [29]. We therefore examined if the extent of calcium deposition in HCASMC was altered under the culture conditions. We treated HCASMC with the induction media for 14 days, and conducted von Kossa staining to examine calcium deposition. Calcium deposition was not detected in GM-treated HCASMC (Figure 2(F)), but moderate deposition was observed in IM- and MCM-treated cells (Figures 2(G) and (H), respectively). As expected, HCASMC treated with IM

A

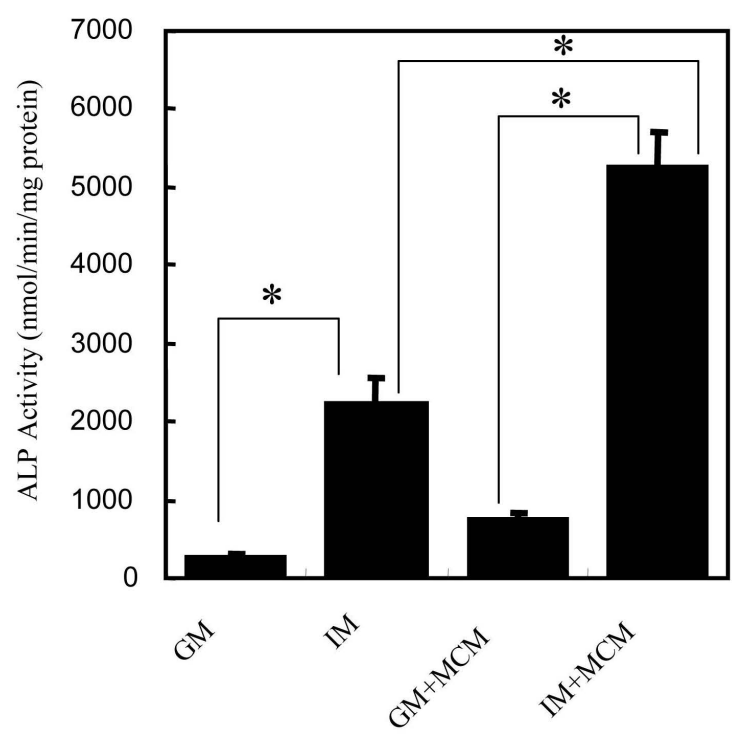

supplemented with MCM showed a large amount of calcium deposit (Figure 2(I)). The extent of calcium deposition was parallel to that of ALP activity, indicating that induction of ALP in VSMC is functionally relevant to calcification in vitro, as reported previously in bovine VSMC [22]. For this reason, we used ALP activity as a marker of in vitro calcification in HCASMC in our subsequent experiments.

\subsection{AGE Fractions and Its Constituents Inhibit ALP Activity in HCASMC.}

Having established the experimental conditions wherein HCASMC possess the ALP activity, we then tested whether AGE and its constituents would inhibit the induction of ALP activity. We added either the hydrophilic or hydrophobic fractions of AGE at concentration equivalent to 5 or $50 \mathrm{mg}-\mathrm{AGE} / \mathrm{ml}$ (see Materials and Methods and Figure 1(b)) into the IM + MCM media. HCASMC were cultured for 6 - 8 days, and the ALP activity was measured in cultured cells.

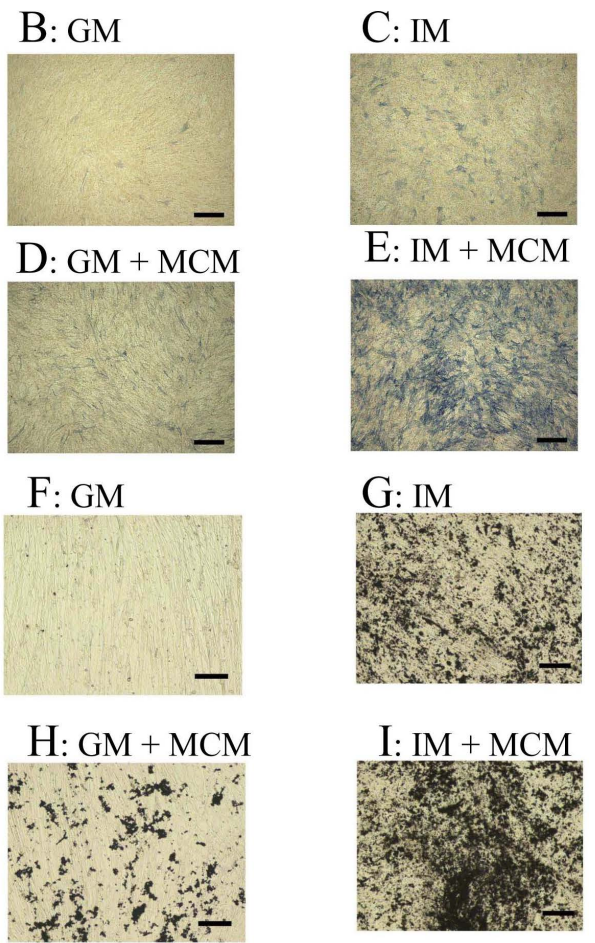

Figure 2. ALP activity and calcium deposition in HCASMC treated with IM supplemented with MCM. (A) HCASMC were cultured in the indicated media for 7 days. ALP activity in whole cell lysates was determined by measuring the release of $p$-nitrophenol from $p$-nitrophenyl phosphate (see Materials and Methods). The data are represented as mean \pm SD $(n=3)$; ((B)-(I)) Histochemical detection of ALP activity and in vitro calcification in HCASMC treated with the induction media. ALP activity ((B)-(E)); HCASMC were cultured in GM (B), IM (C), GM supplemented with 10\% MCM (D), or IM supplemented with $10 \%$ MCM (E) for 7 days, with the medium replenished every 2 - 3 days. Cells were fixed and stained for ALP activity (blue) as described in Materials and Methods. Scale bar represents $500 \mu \mathrm{m}$ (Objective ×4, BIOREVO BZ-9000, KEYENCE). Calcification ((F)-(I)); HCASMC were cultured in the media as described in Histochemical detection of ALP activity for 14 days. Cells were fixed and von Kossa staining was conducted to stain calcium deposition (black). Scale bar represents $100 \mu \mathrm{m}$ (Objective ×20, BIOREVO BZ-9000, KEYENCE). "Significantly difference: $p<0.05$. 
We found that both hydrophilic and hydrophobic fractions of AGE suppressed ALP activity induced by IM + $\mathrm{MCM}$, in a concentration-dependent manner. We next screened compounds in the hydrophobic fraction of AGE (Figure 3). We found that dilignol, DDC, one of the compounds presence in AGE, inhibited the induction of ALP in a concentration-dependent fashion but not DDDC (Figure 4(b)).

\section{Discussion}

It has been known that vascular calcification is a common and clinically significant feature of advanced atherosclerosis on epidemiological observations, i.e. the pathologic calcification of the cardiovascular system can be recognized as mimical osteogenic mechanisms [19]. These calcified lesions express bone-related proteins, such as ALP, bone morphogenetic proteine, runt-related gene product, and osteopontin [3-8]. Also these tissue contains inflammatory cells $[9,10]$. It has been found that the dietary supplementation of AGE retards coronary calcification in high-risk patients having coronary artery disease with calcified plaques in a placebo-controlled, double-blind, randomized clinical study $[19,20]$. This study showed that patients on placebo progressed at a rate of $22.2 \%$ per year, while the AGE reduced progres-

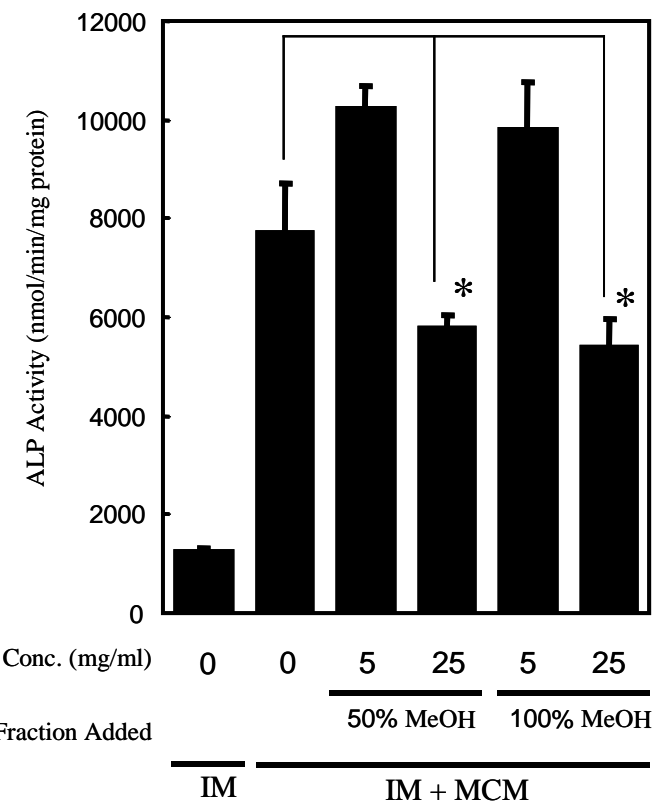

Figure 3. The effect of hydrophobic fractions of AGE on ALP induction by concomitant application of Dex and MCM in HCASMC culture. HCASMC were treated with IM supplemented with MCM with or without AGE fractions at the indicated concentrations for 8 days, and ALP activity in cells was assessed. The data are represented as mean \pm SD $(n=3)$. * Significantly difference: $p<0.05$.

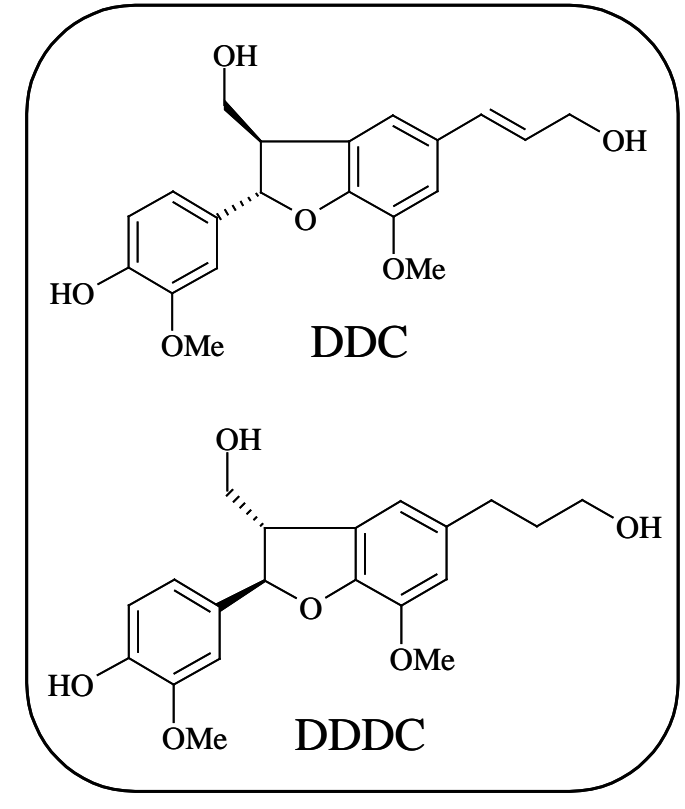

Compound Added

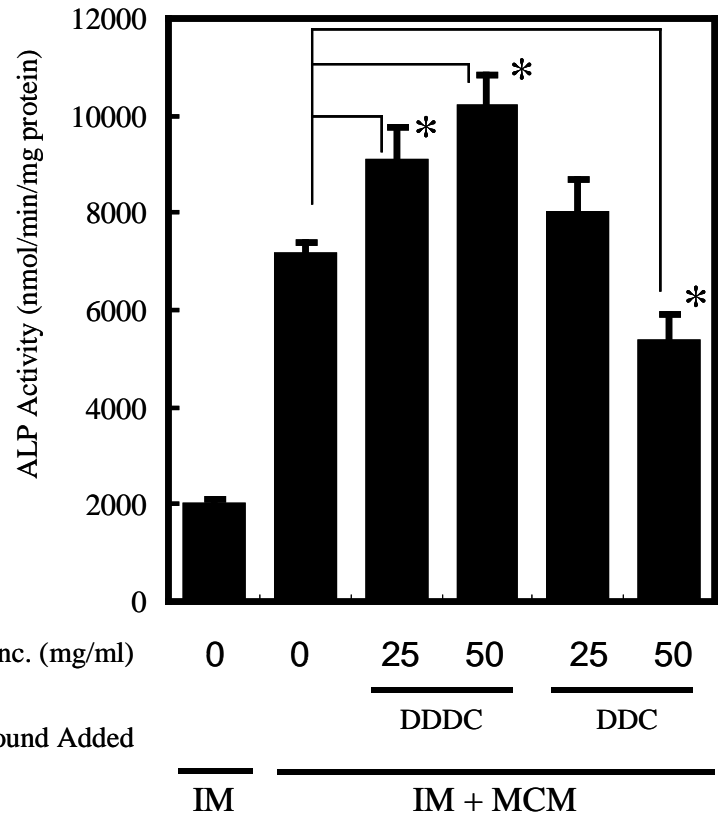

(b)

(a)

Figure 4. The effect of DDC and DDDC on the ALP induction in HCASMC culture. (a) Structure of DDC and DDDC; (b) ALP activity in HCASMC treated with IM supplemented with MCM in the presence of DDC and DDDC at the indicated concentrations for 7 days, and ALP activity in cells was assessed. The data are represented as mean \pm SD $(n=3)$. ${ }^{*}$ Significantly difference: $p<0.05$. 
sion to $7.5 \%$. Additionally, there were no significant change in cholesterol parameter, homocysteine, C-reactive proteine, and cholesterol/HDL rations between the groups, although there was a trend toward improvement of cholesterol parameters. Therefore, retardation of calcification on AGE supplementation may not be related to inhibition of lipid peroxidation or cholesterol lowering effect by AGE. Based on these observations, we hypothesized that the reduction in coronary calcified plaque by supplementation of AGE was partly due to the suppression of osteogenic differentiation in VSMC. It is known that macrophages in calcified plaque modulate the progress of artherosclerosis through the interaction between VSMC and macrophage [30-32]. This system in vitro mimicis events in arthrosclerotic calcified plaques in vivo. In this study we showed that human coronary artery smooth muscle cells (HCASMC) undergo osteogenic conversion by glucocorticoid and the conditioned media from macrophage culture, as an inflammatory stimuli, through the enhancement of ALP activity, one of maker substances for osteoblast differentiation (Figure 2).

Plants produce thousand of compounds and phenolic compounds, one of characteristic groups well known having antioxidant, are essential to the plants physiology having diverse functions such as structure, pigmentation, pollination, pathogen and predator resistance, and growth and development [33]. Consumption of tea and wine has been epidemiologically shown to produce cardiovascular protection effects and its activity was strongly related to antioxidant of phenolic compounds although precise mechanism is still unclear [34]. Negrao et al. reported that polyphenolic compound containing beverages, including beer, wine and tea, show inhibition of ALP activity in human vascular smooth muscle cells in culture study and they also showed ALP inhibition activity by these phenolic constituents, such as resveratrol, epigallocatechin-3-gallate and quercetin, so on [34]. On the other hand, Dai et al. showed that resveratrol enhances proliferation and osteoblastic differentiation, including stimulation of ALP activity in human mesenchymal stem cells [35] and Jeong et al. reported stimulation of ALP activity by a phenolic chemical from hop plant on C2C12 cells [36]. These recent studies suggest that phenolic compounds can modulate differentiation of vascular smooth muscle cells.

We separated AGE in several fraction using polyaromatic adsorbent resin, MCI gel CHP20P (Figure 1(a)). These fractions were evaluated inhibition of ALP activity of VSMC induced by inflammatory stimuli and hydrophobic fraction showed suppression of ALP activity (Figure 3). Recently, several phenolic compounds were identified in hydrophobic fraction of AGE and some of them identified shows high antioxidant activity as same as that of ascorbic acid [24]. We have evaluated the inhibition of ALP activity of these phenolic compounds found in AGE and found that DDC ((+)-(2S,3R)-Dehydrodiconiferyl alcohol) showed inhibition activity (at 153 $\mu \mathrm{M}$ of DDC: equivalent to $50 \mathrm{mg}-\mathrm{AGE} / \mathrm{ml}$ ). However, another choniferyl alcohol compounds found in AGE, DDDC ((-)-(2R,3S)-Dihydrodehydrodiconiferyl alcohol) which is a resemblant compound to DDC, did not show inhibition of ALP activity (Figure 4(b)) although DDC and DDDC shows almost same antioxidant activity [24]. Although antioxidant activity of several polyphenoric compounds were in the same range (EC50 in $\mu \mathrm{M}$ : epicatechin; 4.1, quercetin: 6.1, DDDC: 10.8, DDC; 11.8), ALP inhibition activity of them varied [24,34]. Therefore, ALP inhibition activity may have no relationships with antioxidant activity.

It may be possible that one of mechanisms by which AGE and its constituent prevents vascular calcification is due to the suppression of osteogenic differentiation of VSMC induced by inflammatory mediators. There is no report that compounds with confery alcohol structure inhibit ALP activity in VSMC and this compound is a different type of phenolic compound from phenolic ALP inhibitor reported previously. There are several structural differences between DDC and DDDC, such as absolute configuration in C2 and C3 position and double bond between position of carbon 8 and 9. Since key structure in coniferyl alcohol for inhibition of ALP activity is unclear, we are now in search of other configuration compounds to reveal anti-vascular calcification activity of AGE.

\section{Conclusion}

In summary, we found that VSMC undergo osteoblast differentiation under an inflammatory milieu, which resembles the events leading to the formation of calcified atherosclerotic plaques, through evaluation of ALP activity as one of makers on osteoblast differentiation. In addition, we also found that AGE and its constituent, DDC, inhibit osteoblast differentiation in VSMC, providing a possible mechanism of AGE to retard coronary artery calcification as evidenced by clinical studies $[19,20]$.

\section{REFERENCES}

[1] R. Detrano, A. D. Guerci, J. J. Carr, D. E. Bild, G. Burke, A. R. Folsom, K. Liu, S. Shea, M. Szklo, D. A. Bluemke, D. H. O’Leary, R. Tracy, K. Watson, N. D. Wong and R. A. Kronmal, "Coronary Calcium as a Predictor of Coronary Events in Four Racial or Ethnic Groups,” The New England Journal of Medicine, Vol. 358, No. 13, 2008, pp. 1336-1345.

http://www.nejm.org/doi/full/10.1056/NEJMoa072100 
http://dx.doi.org/10.1056/NEJMoa072100

[2] R. Wayhs, A. Zelinger and P. Raggi, "High Coronary Artery Calcium Scores Pose an Extremely Elevated Risk for Hard Events," The Journal of the American College of Cardiology, Vol. 39, No. 2, 2002, pp. 225-230. http://ac.els-cdn.com/S0735109701017375/1-s2.0-S0735 109701017375-main.pdf?_tid=86dd2444-402c-11e3-a357 -00000aab0f01\&acdnat $=1383004753 \_d 20 e 0 d d d a 97 c b 0 b$ 376a51c8b9db4f802 http://dx.doi.org/10.1016/S0735-1097(01)01737-5

[3] T. Ikeda, T. Shirasawa, Y. Esaki, S. Yoshiki and K. Hirokawa, "Osteopontin mRNA Is Expressed by Smooth Muscle-Derived Foam Cells in Human Atherosclerotic Lesions of the Aorta," The Journal of Clinical Investigation, Vol. 92, No. 6, 1993, pp. 2814-2820.

http://www.ncbi.nlm.nih.gov/pmc/articles/PMC288482/p df/jcinvest00044-0262.pdf

http://dx.doi.org/10.1172/JCI116901

[4] C. M. Shanahan, N. R. Cary, J. C. Metcalfe and P. L. Weissberg, "High Expression of Genes for CalcificationRegulating Proteins in Human Atherosclerotic Plaques," Journal of Clinical Investigation, Vol. 93, 1994, pp. 23932402.

http://www.ncbi.nlm.nih.gov/pmc/articles/PMC294446/p df/jcinvest00035-0101.pdf

http://dx.doi.org/10.1172/JCI117246

[5] C. R. Dhore, J. P. Cleutjens, E. Lutgens, K. B. Cleutjens, P. P. Geusens, P. J. Kitslaar, J. H. Tordoir, H. M. Spronk, C. Vermeer and M. J. Daemen, "Differential Expression of Bone Matrix Regulatory Proteins in Human Atherosclerotic Plaques," Arteriosclerosis, Thrombosis and Vascular Biology, Vol. 21, No. 12, 2001, pp. 1998-2003.

http://atvb.ahajournals.org/content/21/12/1998

http://dx.doi.org/10.1161/hq1201.100229

[6] M. A. Engelse, J. M. Neele, A. L. Bronckers, H. Pannekoek and C. J. de Vries, "Vascular Calcification: Expression Patterns of the Osteoblast-Specific Gene Core Binding Factor Alpha-1 and the Protective Factor Matrix Gla Protein in Human Atherogenesis," Cardiovascular Research, Vol. 52, No. 2, 2001, pp. 281-289.

http://cardiovascres.oxfordjournals.org/content/52/2/281 http://dx.doi.org/10.1016/S0008-6363(01)00375-3

[7] K. L. Tyson, J. L. Reynolds, R. McNair, Q. Zhang, P. L. Weissberg and C. M. Shanahan, "Osteo/Chondrocytic Transcription Factors and Their Target Genes Exhibit Distinct Patterns of Expression in Human Arterial Calcification," Arteriosclerosis, Thrombosis and Vascular Biology, Vol. 23, No. 3, 2003, pp. 489-494.

http://atvb.ahajournals.org/content/23/3/489

http://dx.doi.org/10.1161/01.ATV.0000059406.92165.31

[8] K. Bostrom, K. E. Watson, S. Horn, C. Wortham, I. M. Herman and L. L. Demer, "Bone Morphogenetic Protein Expression in Human Atherosclerotic Lesions," The Journal of Clinical Investigation, Vol. 91, No. 4, 1993, pp. 1800-1809. http://dx.doi.org/10.1172/JCI116391

[9] L. Jonasson, J. Holm, O. Skalli, G. Bondjers and G. K. Hansson, "Regional Accumulations of T Cells, Macrophages, and Smooth Muscle Cells in the Human Atherosclerotic Plaque," Arteriosclerosis, Thrombosis and Vas- cular Biology, Vol. 6, 1986, pp. 131-138. http://atvb.ahajournals.org/content/6/2/131 http://dx.doi.org/10.1161/01.ATV.6.2.131

[10] H. C. Stary, "Lipid and Macrophage Accumulations in Arteries of Children and the Development of Atherosclerosis," The American Journal of Clinical Nutrition, Vol. 72, No. 5, 2000, pp. 1297S-1306S. http://ajcn.nutrition.org/content/72/5/1297s

[11] M. Y. Speer, H. Y. Yang, T. Brabb, E. Leaf, A. Look, W. L. Lin, A. Frutkin, D. Dichek and C. M. Giachelli, "Smooth Muscle Cells Give Rise to Osteochondrogenic Precursors and Chondrocytes in Calcifying Arteries," Circulation Research, Vol. 104, No. 6, 2009, pp. 733-741. http://circres.ahajournals.org/content/104/6/733 http://dx.doi.org/10.1161/CIRCRESAHA.108.183053

[12] A. Kizu, A. Shioi, S. Jono, H. Koyama, Y. Okuno and Y. Nishizawa, "Statins Inhibit in Vitro Calcification of Human Vascular Smooth Muscle Cells Induced by Inflammatory Mediators," Journal of Cellular Biochemisty, Vol. 93, No. 5, 2004, pp. 1011-1019. http://dx.doi.org/10.1002/jcb.20207

[13] A. Shioi, M. Katagi, Y. Okuno, K. Mori, S. Jono, H. Koyama and Y. Nishizawa, "Induction of Bone-Type Alkaline Phosphatase in Human Vascular Smooth Muscle Cells: Roles of Tumor Necrosis Factor-Alpha and Oncostatin M Derived from Macrophages," Circulation Research, Vol. 91, No. 1, 2002, pp. 9-16.

http://circres.ahajournals.org/content/91/1/9 http://dx.doi.org/10.1161/01.RES.0000026421.61398.F2

[14] H. Amagase, B. L. Petesch, H. Matsuura, S. Kasuga and Y. Itakura, "Intake of Garlic and Its Bioactive Components,” Journal of Nutrition, Vol. 131, No. 3, 2001, pp. 955S-962S. http://jn.nutrition.org/content/131/3/955S

[15] M. Steiner, A. H. Khan, D. Holbert and R. I. Lin, “A Double-Blind Crossover Study in Moderately Hypercholesterolemic Men that Compared the Effect of Aged Garlic Extract and Placebo Administration on Blood Lipids," American Journal of Clinical Nutrition, Vol. 64, No. 6, 1996, pp. 866-870. http://ajcn.nutrition.org/content/64/6/866.long

[16] K. Rahman and D. Billington, "Dietary Supplementation with aged Garlic Extract Inhibits ADP-Induced Platelet Aggregation in Humans,” Journal of Nutrition, Vol. 130, No. 1, 2000, pp. 2662-2665. http://jn.nutrition.org/content/130/11/2662

[17] M. Steiner and W. Li, “Aged Garlic Extract, a Modulator of Cardiovascular Risk Factors: A Dose-Finding Study on the Effects of AGE on Platelet Functions," Journal of Nutrition, Vol. 131, No. 3S, 2001, pp. 980S-984S. http://jn.nutrition.org/content/131/3/980S

[18] B. H. Lau, "Suppression of LDL Oxidation by Garlic," Journal of Nutrition, Vol. 131, No. 3S, 2001, pp 985S988S. http://jn.nutrition.org/content/131/3/985S

[19] M. J. Budoff, “Aged Garlic Extract Retards Progression of Coronary Artery Calcification,” Journal of Nutrition, Vol. 136, No. 3S, 2006, pp. 741S-744S. http://jn.nutrition.org/content/136/3/741S

[20] M. J. Budoff, J. Takasu, F. R. Flores, Y. Niihara, B. Lu, B. 
H. Lau, R. T. Rosen and H. Amagase, "Inhibiting Progression of Coronary Calcification Using Aged Garlic Extract in Patients Receiving Statin Therapy: A Preliminary Study," Preventive Medicine, Vol. 39, No. 5, 2004, pp. 985-991. http://dx.doi.org/10.1016/j.ypmed.2004.04.012

[21] H. Sowa, H. Kaji, L. Canaff, G. N. Hendy, T. Tsukamoto, T. Yamaguchi, K. Miyazono, T. Sugimoto and K. Chihara, "Inactivation of Menin, The Product of the Multiple Endocrine Neoplasia Type 1 Gene, Inhibits the Commitment of Multipotential Mesenchymal Stem Cells into the Osteoblast lineage,” The Journal of Biological Chemistry, Vol. 278, No. 23, 2003, pp. 21058-21069. http://dx.doi.org/10.1074/jbc.M302044200

[22] A. Shioi, Y. Nishizawa, S. Jono, H. Koyama, M. Hosoi and H. Morii, "Beta-Glycerophosphate Accelerates Calcification in Cultured Bovine Vascular Smooth Muscle Cells," Arteriosclerosis, Thrombosis and Vascular Biology, Vol. 15, No. 11, 1995, pp. 2003-2009. http://atvb.ahajournals.org/content/15/11/2003 http://dx.doi.org/10.1161/01.ATV.15.11.2003

[23] N. Morihara, M. Hayama and H. Fujii, "Aged Garlic Extract Scavenges Superoxide Radicals," Plant Foods for Human Nutrition, Vol. 66, No. 1, 2011, pp. 17-21. http://dx.doi.org/10.1007/s11130-011-0216-6

[24] T. Matsutomo, T. D. Stark and T. Hofmann, "In Vitro Activity-Guided Identification of Antioxidants in Aged Garlic Extract," Journal Agricultural and Food Chemistry, Vol. 61, No. 12, 2013, pp. 3059-3067. http://pubs.acs.org/doi/abs/10.1021/jf305549g http://dx.doi.org/10.1021/jf305549g

[25] L. C. Hofbauer, J. Schrader, U. Niebergall, V. Viereck, A. Burchert, D. Horsch, K. T. Preissner and M. Schoppet, "Interleukin-4 Differentially Regulates Osteoprotegerin Expression and Induces Calcification in Vascular Smooth Muscle Cells," Thrombosis and Haemostasis, Vol. 95, No. 4, 2006, pp. 708-714. http://dx.doi.org/10.1160/TH05-12-0800

[26] A. Van Campenhout, C. S. Moran, A. Parr, P. Clancy, C. Rush, H. Jakubowski and J. Golledge, "Role of Homocysteine in Aortic Calcification and Osteogenic Cell Differentiation,” Atherosclerosis, Vol. 202, No. 2, 2009, pp. 557-566.

http://dx.doi.org/10.1016/j.atherosclerosis.2008.05.031

[27] C. Goettscha, C. Hamannb, U. Hempelc, M. Raunera and L. Hofbauera, "Oxidized Lipids Induce Vascular Calcification through the Nfat and Stat3 Pathway," Bone, Vol. 44, Suppl. 2, 2009, pp. S297-S298. http://dx.doi.org/10.1016/j.bone.2009.03.542

[28] M. Melino, V. L. Gadd, G. V. Walker, R. Skoien, H. D. Barrie, D. Jothimani, L. Horsfall, A. Jones, M. J. Sweet, G. P. Thomas, A. D. Clouston, J. R. Jonsson and E. E. Powell, "Macrophage Secretory Products Induce an Inflammatory Phenotype in Hepatocytes," World Journal of
Gastroenterology, Vol. 18, No. 15, 2012, pp. 1732-1744. http://dx.doi.org/10.3748/wjg.v18.i15.1732

[29] I. J. Lorch, "Alkaline Phosphatase and the Mechanism of Ossification,” The Journal of Bone and Joint Surgery, Vol. 31B, No. 1, 1949, pp. 94-99.

http://boneandjoint.org.uk/highwire/filestream/9277/field highwire_article_pdf/0/94.full-text.pdf

[30] H. C. Stary, "Lipid and Macrophage Accumulations in Arteries of Children and the Development of Atheroscleosis," American Journal of Clinical Nutrition, Vol. 72, No. 5, 2000, pp. 1297S-1306S. http://ajcn.nutrition.org/content/72/5/1297s.full.pdf+html

[31] M. Jeziorska, C. McCollum and D. E. Woolley, "Calcification in Artherosclerotic Plaque of Human Carotid Artreies: Associations with Mast Cells and Macrophages,” The Journal of Pathology, Vol. 185, No. 1, 1998, pp. 1017.

http://dx.doi.org/10.1002/(SICI)1096-9896(199805)185:1 $<10::$ AID-PATH71>3.0.CO;2-0

[32] Y. Tintut, J. Patel, M. Territo, T. Saini, F. Parhami and L. L. Demer, "Monocyte/Macrophage Regulation of Vascular Calcification in Vitro,” Circulation, Vol. 105, No. 5, 2002, pp. 650-655.

http://circ.ahajournals.org/content/105/5/650.long http://dx.doi.org/10.1161/hc0502.102969

[33] G. G. Duthie, S. J. Duhie and J. A. M. Kyle, "Plant Polyphenols in Cancer and Heart Disease: Implications as Nutritional Antioxidants,” Nutrition Research Reviews, Vol. 13, No. 1, 2000 pp. 79-105.

http://journals.cambridge.org/download.php?file=\%2FNR R\%2FNRR13_01\%2FS0954422400000056a.pdf\&code $=0$ 2620b05cb23433b215d621ee092fd38 http://dx.doi.org/10.1079/095442200108729016

[34] M. R. Negrao, E. Keating, A. Faria, I. Azevedo and M. J. Martins, “Acute Effect of Tea, Wine, Beer and Polyphenols on Ecto-Alkaline Phosphatase Activity in Human Vascular Smooth Muscle Cells,” Journal of Agricultural and Food Chemistry, Vol. 54, No. 12, 2006, pp. 49824988. http://pubs.acs.org/doi/pdf/10.1021/jf060505u

[35] Z. Dai, Y. Li, L. D. Quarles, T. Song, W. Pan, H. Zhou and Z. Xiao, "Resveratrol Enhances Proliferation and Osteoblastic Differentiation in Human Mesenchymal Stem Cells via ER-Dependent ERK1/2 Activation,” Phytomedicine, Vol. 14, No. 12, 2007, pp. 806-814.

[36] H. M. Jeong, E. H. Han, Y. H. Jin, Y. H. Choi, K. Y. Lee and H. G. Jeong, "Xanthohumol from the Hop Plant Stimulates Osteoblast Differentiation by RUNX2 Activation," Biochemical and Biophysical Research Communications, Vol. 409, No. 1, 2011, pp. 82-89. http://dx.doi.org/10.1016/j.bbrc.2011.04.113 